leaf stage, the plants were inoculated with 56

\title{
Wild and Cultivated Strawberries Can Tolerate or Resist Root-lesion Nematode
}

\author{
John W. Potter \\ Agriculture Canada Research Station, Vineland Station, Ont. LOR 2EO, \\ Canada
}

\author{
Adam Dale \\ Horticultural Research Institute of Ontario, Box 587, Simcoe, Ont. N3Y 4N5, \\ Canada
}

Additional index words. Fragaria $\times$ ananassa, Fragaria chiloensis, Fragaria virginiana,

Pratylenchus penetrans

\begin{abstract}
Intraspecific crossing of 'Guardian' and 'Midway' cultivated strawberry (Fragaria $\times$ ananassa Duch.) produced a family of genotypes, some of which suppressed root-lesion nematode [Pratylenchus penetrans (Cobb)] population counts and produced large berries and high yield. Unlike 'Midway', 'Guardian' also suppressed $P$. penetrans. Among several beach strawberry [Fragaria chiloensis (L.) Duch.] and woodland strawberry (Fragaria virginiana Duch.) genotypes, variation was found in resistance and tolerance to root-lesion nematodes. Three $F$. chiloensis genotypes showed tolerance, and at least two genotypes may be somewhat resistant. Three $F$. virginiana genotypes also were tolerant, and three were resistant. Also, one ('Little Cataraqui 4') combined root growth vigor with nematode resistance. We concluded that exploitable genetic diversity in vigor and reaction to rootlesion nematodes exists in wild Fragaria and in $F$. ×ananassa.
\end{abstract}

The cultivated strawberry, Fragaria $\times$ ananassa is a woodland (Fragaria virginiana) and beach strawberry [Fragaria chiloensis (L.)] hybrid. All three species are root-lesion nematode [Pratylenchus penetrans (Cobb)] hosts (Goheen and Braun, 1956; Hildebrand, 1934; McElroy, 1977; Steiner, 1931).

Hildebrand and West (1941) first suggested that root-lesion nematodes were involved in strawberry root rot. Initially, many researchers regarded root-lesion nematodes as synergizing with other pathogens, especially Verticillium, which itself is of questionable pathogenicity. However, Chen and Rich (1962) and Townshend (1963a) demonstrated that $P$. penetrans was pathogenic on strawberry.

Several nematologists have published host association reports of root-lesion nematodes with selected varieties of $F$. ×ananassa (Chapman, 1956; Goheen and Smith, 1956; Townshend, 1962). Others have observed differences in root-lesion nematode reproduction among the species varieties (Adams and Hickman, 1970; Kimpinski, 1985; Szczygiel, 1981; Vrain, 1985). Szczygiel (1981) evaluated 28 strawberry varieties in pots for $P$. penetrans susceptibility and concluded that root necrosis and growth reduction should be considered indicators of nematode-induced damage. Various edaphic and biotic factors

Received for publication 1 Oct. 1993. Accepted for publication 20 Feb. 1994. We gratefully acknowledge L. Wainman's technical assistance. The cost of publishing this paper was defrayed in part by the payment of page charges. Under postal regulations, this paper therefore must be hereby marked adver tisement solely to indicate this fact. may affect the nematode damage threshold (Potter and Dale, 1991), which may be $>500$ nematodes per kilogram of soil (Szczygiel, 1983).

In this paper, we follow Cook and Evans' (1987) terminology, which considers resistance and susceptibility to relate to nematode reproduction and tolerance to describe host injury. Plant sources that are resistant (support few lesion nematodes or suppress lesion nematode counts) or are tolerant (do not exhibit growth reduction or root necrosis) are necessary to improve the commercial strawberry reaction to nematodes. Our objectives were to evaluate 1) the improvement of resistance or tolerance to nematodes through intraspecific crosses between $F$. xananassa varieties and (2) resistance or tolerance sources among $F$. chiloensis and $F$. virginiana genotypes.

\section{Materials and Methods}

Intraspecific F. Xananassa crosses. This experiment was conducted in two phases: 1) evaluation in the greenhouse of nematode multiplication on two $F$. Xananassa parents and crosses of these parents and 2) fruit yield evaluation in the field from the parents and crosses. Based on Szczygiel's (1981) work, 'Midway' and 'Guardian' (which supported large and small populations of $P$. penetrans, respectively) strawberries were selected as parents. These varieties were crossed and selfed to produce three families.

Plants were grown from the seed and planted in $50 \times 35 \times 10$-cm $(17.5$-liter $)$ rubber trays of potting soil, with 45 plants per tray and one tray per family in a greenhouse. At the four-
$P$. penetrans per plant. Nematodes were injected in $10 \mathrm{ml}$ aqueous suspension into the root zone using a syringe; we obtained nematode inoculum from a greenhouse culture of timothy grass roots (Phleum pratense L.). Runner plants from the seedlings were rooted and retained. After 14 weeks, the inoculated plants were removed from the trays, and roots were washed. Roots were excised from the crowns, and nematodes were mist-extracted from each root system for 2 weeks (Ayoub, 1980). Following extraction, each root mass was oven-dried at $72 \mathrm{C}$ for $24 \mathrm{~h}$. The extracted nematodes were counted with a stereoscopic microscope (Ernst Leitz Gmbh, Wetzlar, Germany) at $\times 50$. The number of nematodes per gram of dry root was calculated by dividing the number of extracted nematodes per root system by the dry root weight.

From the 45 plants in each of the three crosses, 30 genotypes were selected for further greenhouse testing after the number of nematodes in the roots was counted. Two genotypes of selfed 'Midway', 10 of selfed 'Guardian', and 18 of 'Guardian' $x$ 'Midway' fitted the selection criterion of having a relatively low nematode count $(<25$ per gram of root). Five runner plants per selection were grown in $10-\mathrm{cm}(600-\mathrm{ml})$ clay pots in $450 \mathrm{~g}$ of steam-pasteurized soil. They were inoculated with $1000 P$. penetrans injected in a $10-\mathrm{ml}$ aqueous suspension into the root zone. Pots were placed on a greenhouse bench in a completely randomized design and were grown for 14 weeks at $25 \mathrm{C}$. Nematodes were extracted from the entire root system for 2 weeks by mistifier (Ayoub, 1980). The number of nematodes per gram of dry root was calculated as previously explained. Nematodes also were extracted from a randomly selected 50 -g soil sample per pot using the Baermann pan method (Townshend, 1963b), and the soil per pot was weighed. The number of nematodes in the soil per pot was calculated from the number in a 50 -g soil aliquot. The total number of nematodes in soil plus root was derived by adding the number extracted from the entire root and the number per pot of soil. The original and derived variables were transformed using a $\log _{10}(x+1)$ transformation and subjected to analysis of variance and least significant difference test (SAS Institute, 1989).

In 1988, the 30 selected genotypes were planted in the field at Horticultural Expt. Station, Simcoe, Canada, for fruiting evaluation. Each genotype was planted as a single 10plant row, $0.6 \mathrm{~m}$ between plants, and $1.2 \mathrm{~m}$ between rows, with plots containing 'Bounty' and 'Vantage' as standards. In 1989, genotypes were evaluated for berry size and yield. All marketable fruit ( $>2 \mathrm{~cm}$ in diameter) were harvested twice weekly. A 50-berry sample per genotype was weighed, and a weighted berry weight was calculated.

Fragaria chiloensis genotypes. Washington State Univ. Western Washington Research and Extension Center, Puyallup, provided F.chiloensis plant material. Five plants each from 13 genotypes plus 'Guardian' and 'Redcoat' were potted in $10-\mathrm{cm}(600-\mathrm{ml})$ pots 
with potting soil and kept in a greenhouse at 25C. Pots were placed in a completely randomized design. Plants were inoculated with 210 P. penetrans per plant, injected in $12 \mathrm{ml}$ water into the potting mix, and were grown in the greenhouse. After 20 weeks, the plants were removed from pots and as much of the peat-based potting mix as possible was washed off the roots in a stream of tap water. The fresh roots were blotted dry on paper towels, fresh weights recorded, and nematodes extracted by mistifier as previously explained. Oven-dried roots were weighed, the extracted nematodes were counted, and statistical analysis was performed as previously explained.

Fragaria virginiana genotypes. Wild $F$. virginiana plants collected from 20 locations in southern Ontario (between $42^{\circ} \mathrm{N}$ and $46^{\circ} \mathrm{N}$ lat.) were grown at Simcoe. At the five-leaf stage, five plants of each genotype were potted in $1600 \mathrm{~g}$ of a Delhi sandy loam soil in $15-\mathrm{cm}$ (1.6-liter) plastic pots and inoculated with $1000 P$. penetrans injected in a $25-\mathrm{ml}$ aqueous suspension into the root zone. Ten 'Redcoat' plants and eight each of 'Guardian' and 'Midway' were infested similarly for comparison. Pots were placed in a completely randomized design in a greenhouse at $25 \mathrm{C}$. All plants were grown for 14 weeks, during which time the runners and blossoms were removed. Then the nematodes were recovered from complete root systems by mist extraction and randomly selected 50-g soil aliquots. Statistical analyses were performed as previously described.

\section{Results and Discussion}

Intraspecific F. Xananassa crosses. In the greenhouse evaluation, 'Guardian' supported the fewest nematodes per gram of dry root and the third fewest nematodes in soil plus root; 'Midway' was near the ranking midpoint for each criterion (Table 1). Within the 'Guardian' $x$ 'Midway' family, the genotypes designated $6.01,6.03,6.15,6.31$, and 6.40 had low counts, but $6.05,6.07,6.27,6.38$, and 6.45 had high counts. Of the former group, all produced high dry-root weights, whereas among the latter group, only clone 6.05 produced a high dry-root weight.

Although berry size and yield were not correlated with the total nematodes in soil plus $\operatorname{root}(r=0.16$ and 0.01 , respectively; $P \leq 0.05)$, some genotypes that carried low nematode populations (6.01, 6.03, and 6.15) also had large berries and high yield.

Fragaria chiloensis genotypes. A high degree of variability was evident in the number of nematodes per gram dry root $(\mathrm{CV}=104)$; each $F$. chiloensis genotype had one plant in five with a low nematode population. On the assumption that the low count might have resulted from death of the nematode inoculum, the data were reanalyzed using the remaining four replicates. HMl and 'Del Norte' supported the highest nematode populations in their root systems, whereas CL5, CA11, and CA12 supported few (Table 2). Using a general linear-model contrast analysis (SAS Institute, 1989), 'Guardian' and 'Redcoat' roots were significantly $(P \leq 0.05)$ heavier than those of the F. chiloensis genotypes. The two varieties also supported significantly fewer lesion nematodes per gram dry root than DL40, HM1, FS20, BSP14, LCM10, or CL2 (Table 2).

Table 1. Pratylenchus penetrans populations in genotypes of selfed, parental, and crossed 'Guardian' and 'Midway' strawberry $(F$. Xananassa) grown in greenhouse pots for 14 weeks $(\mathrm{N}=5)$.

\begin{tabular}{|c|c|c|c|c|c|}
\hline \multirow[b]{2}{*}{$\begin{array}{l}\text { Genotype } \\
\text { designation }\end{array}$} & \multicolumn{2}{|c|}{ Nematodes $^{\mathrm{z}}$} & \multirow[b]{2}{*}{$\begin{array}{c}\text { Dry root } \\
\text { wt }(\mathrm{g})\end{array}$} & \multicolumn{2}{|c|}{ Berry ${ }^{y}$} \\
\hline & $\begin{array}{l}\text { No./gram } \\
\text { dry root }\end{array}$ & $\begin{array}{l}\text { Total no. in } \\
\text { soil + root }\end{array}$ & & $\begin{array}{l}\mathrm{Wt} \\
(\mathrm{g})\end{array}$ & $\begin{array}{r}\text { Yield } \\
\left(\mathrm{t} \cdot \mathrm{ha}^{-1}\right)\end{array}$ \\
\hline 6.45 & 1430 & 680 & 0.4 & 10.0 & 7.7 \\
\hline 6.38 & 990 & 600 & 0.5 & 7.7 & 4.6 \\
\hline 6.27 & 490 & 660 & 1.2 & 7.6 & 18.5 \\
\hline $7.15(\mathrm{G})$ & 480 & 700 & 1.2 & 17.1 & 1.8 \\
\hline 6.07 & 460 & 590 & 0.9 & 9.2 & 14.6 \\
\hline 6.44 & 440 & 250 & 0.6 & 10.7 & 9.2 \\
\hline 6.20 & 380 & 260 & 0.5 & 9.5 & 12.8 \\
\hline $7.05(\mathrm{G})$ & 340 & 700 & 3.1 & 12.1 & 6.2 \\
\hline 6.05 & 260 & 510 & 2.5 & 9.6 & 9.4 \\
\hline $7.20(\mathrm{G})$ & 210 & 480 & 2.8 & 8.3 & 10.9 \\
\hline 6.11 & 200 & 280 & 2.1 & 13.4 & 15.6 \\
\hline 6.02 & 180 & 330 & 3.9 & 6.4 & 7.2 \\
\hline 6.43 & 180 & 440 & 1.4 & 11.2 & 20.6 \\
\hline 6.30 & 170 & 530 & 2.4 & 9.2 & 11.3 \\
\hline $7.35(\mathrm{G})$ & 150 & 470 & 1.8 & 10.3 & 13.9 \\
\hline 6.16 & 150 & 260 & 0.6 & 9.5 & 13.9 \\
\hline 6.41 & 130 & 590 & 4.3 & 11.9 & 13.3 \\
\hline 7.27 (G) & 110 & 470 & 3.0 & 9.9 & 9.5 \\
\hline Midway & 110 & 390 & 1.6 & ---w & --- \\
\hline $5.01(\mathrm{M})$ & 80 & 380 & 2.5 & 7.4 & 4.6 \\
\hline 6.40 & 70 & 220 & 2.5 & 8.7 & 10.2 \\
\hline $7.45(\mathrm{G})$ & 70 & 240 & 3.2 & 6.6 & 9.0 \\
\hline $7.30(\mathrm{G})$ & 60 & 490 & 4.0 & --- & --- \\
\hline 6.15 & 60 & 280 & 1.4 & 11.6 & 9.5 \\
\hline 7.08 (G) & 60 & 330 & 5.3 & 7.9 & 2.8 \\
\hline 6.01 & 60 & 180 & 1.8 & 10.7 & 9.4 \\
\hline 6.31 & 30 & 190 & 5.1 & 7.6 & 16.3 \\
\hline 7.41 (G) & 20 & 260 & 3.1 & 10.3 & 9.2 \\
\hline 6.03 & 20 & 290 & 3.5 & 11.7 & 11.5 \\
\hline 7.12 (G) & 20 & 150 & 6.1 & 6.2 & 14.5 \\
\hline $5.44(\mathrm{M})$ & 10 & 70 & 1.7 & 4.6 & 7.0 \\
\hline Guardian & 10 & 170 & 1.7 & --- & --- \\
\hline Vantage $^{\mathrm{v}}$ & --- & --- & --- & 10.8 & 18.7 \\
\hline Bounty & --- & --- & --- & 9.9 & 22.1 \\
\hline $\operatorname{LSD}_{(0.05)}$ & 589 & 422 & 2.7 & & \\
\hline
\end{tabular}

${ }^{2}$ Data from greenhouse pot trials; nematodes per gram dry root $=$ number nematodes extracted from root $\div$ dry root weight.

yField-grown for berry production data only.

×Genotypes designated "7.-- G" are selfed 'Guardian', "5.-- M" are selfed 'Midway', "6.--" are crosses of 'Guardian' $\times$ 'Midway'.

"Data not taken.

'VVantage' and 'Bounty' = standards of berry size and yield only.

Table 2. Pratylenchus penetrans populations in genotypes of Fragaria chiloensis varieties and breeding lines and in 'Guardian' and 'Redcoat' $(F$. ×ananassa) grown in greenhouse pots for 20 weeks $(\mathrm{N}=5)$.

\begin{tabular}{lccc}
\hline \hline \multirow{2}{*}{$\begin{array}{l}\text { Genotype } \\
\text { designation }\end{array}$} & \multicolumn{2}{c}{ Nematodes } & \\
\cline { 2 - 3 } DL40 & $\begin{array}{c}\text { No./gram } \\
\text { dry root }^{2}\end{array}$ & $\begin{array}{c}\text { Total no./ } \\
\text { root }\end{array}$ & $\begin{array}{c}\text { Dry root } \\
\text { wt (g) }\end{array}$ \\
HM1 & 1970 & 1220 & 0.6 \\
FS20 & 1850 & 2870 & 1.5 \\
BSP14 & 1820 & 1160 & 0.6 \\
LCM10 & 1720 & 840 & 0.5 \\
CL2 & 1640 & 1360 & 0.8 \\
Del Norte & 1630 & 1290 & 0.8 \\
TR4 & 1610 & 2520 & 1.6 \\
CA12 & 1270 & 1220 & 1.0 \\
RCP37 & 1140 & 620 & 0.5 \\
ZB4 & 950 & 940 & 1.0 \\
CAll & 800 & 1580 & 2.0 \\
CL5 & 550 & 540 & 1.0 \\
Redcoat & 600 & 760 & 1.3 \\
Guardian & 90 & 380 & 4.3 \\
LSD $_{0.05}$ & 30 & 170 & 5.3 \\
\hline
\end{tabular}

${ }^{2}$ Nematodes per gram dry root $=$ number nematodes extracted from root $\div$ dry root weight. 
virginiana genotypes 'Townsend 17 ' and 'St. Davids l' ranked between 'Guardian' and genotype 'Little Cataraqui 4' supported fewer nematodes per gram of dry root than 'Redcoat' and slightly more than either 'Guardian' or 'Midway'. The genotype 'Little Cataraqui 4' also produced a higher root weight than any of the three $F$. ×ananassa varieties. Of 13 genotypes that supported more than the mean number of nematodes per gram of root (336), 10 also had more than the mean total number in soil plus root (1545). By both criteria, the est number of nematodes.

Our work with $F$. Xananassa genotypes (Table 1) indicates that there is variation in nematode tolerance and resistance (or suppressiveness). We found that 'Midway' supported a slightly larger total population than 'Guardian'. Our ranking agrees with Szczygiel's (1981) findings with 'Guardian' and 'Midway' and supports Kimpinski's (1985) results with 'Redcoat'. The variation range in 'Guardian' selfed and 'Guardian' $x$ 'Midway' genotypes suggests that progress can be made to increase either tolerance or resistance. Some genotypes that suppressed nematodes and produced a relatively vigorous root system also had large fruit and good fruit quality (data not shown). This group of clones could be useful as parents for developing lesion-nematode resistant or tolerant varieties without resorting to wild genotypes.

The variability among $F$. chiloensis and $F$. virginiana genotypes precluded determining whether genetic resistance to $P$. penetrans in the hybrid $F$. ×ananassa is derived preferentially from one or the other wild species. Some suppressive genotypes were present in $F$. virginiana (Table 3); however, the slight dif'Redcoat' for this criterion (Table 3). Only the genotype 'Brockville 28' supported the great-

ference between $F$. chiloensis genotypes CL5 and CA11 and 'Guardian' or 'Redcoat' (Table 2) supports the possibility that resistance also may be found in $F$. chiloensis. More $F$. chiloensis genotypes should be tested for resistance. In addition, the genotypes HM1, ZB4, and 'Del Norte' may be tolerant as they grow and produce reasonable root weights, despite a high nematode presence.

The basis of nematode tolerance in $F$. chiloensis is not clearly understood. However, according to Hancock (1991), the genotype RCP37 had a higher photosynthesis and $\mathrm{CO}_{2}$ assimilation rate, due in part to thicker spongy mesophyll in the leaf. Archbold and Zhang (1991) reported that the genotype BSP14 exhibited drought stress resistance through osmotic modification that resulted in increased soluble sugar concentration in the plant under drought stress. Because nematodes metabolize sugars while feeding (Jones, 1981), a plant with the capacity to produce excess sugars might be better able to withstand parasitic feeding by nematodes than one that lacks this capability. In our study, genotypes RCP 37 and BSP14 were among the $F$. chiloensis genotypes that supported a medium number of nematodes on a lesser root system. Further studies on correlation of plant physiology with nematode tolerance among $F$. chiloensis genotypes seem warranted.

Among the wild $F$. virginiana genotypes examined thus far, great diversity exists in growth vigor (Table 3 ). The genotypes 'Oro 11', 'Normandale 3', and 'HES 9' that supported many nematodes also produced vigorous roots and may be examples of tolerance as are HMl, ZB4, and 'Del Norte'.

Diversity, and hence resistance to Pratylenchus penetrans, in cultivated strawberries can be increased by introducing unim-

Table 3. Pratylenchus penetrans populations in genotypes of Fragaria virginiana and in 'Guardian', 'Midway', and 'Redcoat' ( $F$. xananassa) grown in greenhouse pots for 14 weeks $(\mathrm{N}=5)$.

\begin{tabular}{|c|c|c|c|}
\hline \multirow[b]{2}{*}{ Genotype and location no. } & \multicolumn{2}{|c|}{ Nematodes } & \multirow[b]{2}{*}{ Dry root $(\mathrm{g})$} \\
\hline & $\begin{array}{l}\text { No./gram } \\
\text { dry root }^{z}\end{array}$ & $\begin{array}{l}\text { Total no. in } \\
\text { soil + root }\end{array}$ & \\
\hline Brockville 28 & 1010 & 3680 & 3.0 \\
\hline Packenham 15 & 730 & 2780 & 3.3 \\
\hline Normandale 3 & 550 & 3240 & 4.5 \\
\hline Alfred 10 & 540 & 1640 & 2.6 \\
\hline Aubrey Lake 21 & 500 & 1470 & 2.0 \\
\hline St. Davids 1 & 450 & 530 & 0.7 \\
\hline St. Williams 24 & 430 & 2730 & 5.9 \\
\hline Oro 11 & 420 & 3040 & 4.9 \\
\hline H.E.S., Simcoe 9 & 420 & 2190 & 4.0 \\
\hline Hillier 16 & 390 & 1650 & 3.9 \\
\hline Balls Falls 23 & 360 & 1570 & 2.6 \\
\hline St. Andre 4 & 350 & 1910 & 2.6 \\
\hline Jordan 2 & 340 & 1390 & 3.3 \\
\hline Lions Head 22 & 240 & 1070 & 3.6 \\
\hline Normandale Fish Hatchery 2 & 240 & 1310 & 5.1 \\
\hline Saugeen River 20 & 230 & 1330 & 3.8 \\
\hline Sauble Beach 19 & 220 & 1140 & 3.8 \\
\hline Townsend 17 & 200 & 810 & 2.6 \\
\hline Silverlake 17 & 190 & 1140 & 3.2 \\
\hline Redcoat & 190 & 980 & 3.9 \\
\hline Little Cataraqui 4 & 80 & 1450 & 4.7 \\
\hline Midway & 70 & 280 & 3.3 \\
\hline Guardian & 60 & 290 & 3.6 \\
\hline $\mathrm{LSD}_{0.05}$ & 476 & 1875 & 0.9 \\
\hline
\end{tabular}

${ }^{2}$ Nematodes per gram dry root $=$ number nematodes extracted from root $\div$ dry root weight. proved wild germplasm (Scott and Lawrence, 1975; Sjulin and Dale, 1987). Several genotypes might be useful in this regard. The genotype 'Little Cataraqui 4' supported few nematodes and produced a higher root weight than $F$. Xananassa varieties. The genotype 'Normandale Fish Hatchery 2', which ranked below the mean number of nematodes by both criteria and had the second highest dry root weight, could be useful as a growth vigor source, exceeding that of the $F$. Xananassa varieties.

Our work, like that of Szczygiel (1981) and Vrain (1985), has considered only a limited selection of genotypes and varieties, but it has indicated diversity that may be exploitable. Further screening is needed to examine the potential usefulness of a wider range of Fragaria genotypes in developing root-lesion nematode resistance or tolerance.

\section{Literature Cited}

Adams, R.E. and C.E. Hickman. 1970. Influence of nematicidal treatments and fungicidal sprays on yield of strawberries. Plant Dis. Rptr. 54:923926.

Archbold, D.D. and B. Zhang. 1991. Drought stress resistance in Fragaria species, p. 138-144. In: A. Dale and J.J. Luby (eds.). The strawberry into the 21st century. Timber Press, Portland, Ore.

Ayoub, S.M. 1980. Plant nematology, An agricultural training aid. NemaAid Publications, Sacramento, Calif.

Chapman, R.A. 1956. Plant parasitic nematodes associated with strawberries in Kentucky. Plant Dis. Rptr. 40:179-181.

Chen, T. and A.E. Rich. 1962. Pathogenicity of Pratylenchus penetrans on strawberry and Ladino white clover seedlings. Phytopathology 52:922-923.

Cook, R. and K. Evans. 1987. Resistance and tolerance, p. 179-231. In: R.H. Brown and B.R. Kerry (eds.). Principles and practice of nematode control in crops. Academic, Sydney.

Goheen, A.C. and A.J. Braun. 1956. Some parasitic nematodesassociated with wild strawberry plants in woodlands in Maryland. Plant Dis. Rptr. 40:43.

Goheen, A.C. and J.B. Smith. 1956. Effects of inoculation of strawberry roots with meadow nematodes, Pratylenchus penetrans. Plant Dis. Rptr. 40:146-149.

Hancock, J.F. 1991. Photosynthesis in strawberries and the possibility of genetic improvement, $\mathrm{p}$. 133-137. In: A. Dale and J.J. Luby (eds.). The strawberry into the 21st century. Timber Press, Portland, Ore.

Hildebrand, A.A. 1934. Recent observations on strawberry root rot in the Niagara Peninsula. Can. J. Res. 11:10-31.

Hildebrand, A.A. and P.M. West. 1941. Strawberry root rot in relation to microbiological changes induced in root rot soil by the incorporation of certain cover crops. Can. J. Res. 19:183-198.

Jones, M.G.K. 1981. The development and function of plant cells modified by endoparasitic nematodes, p. 255-280. In: B.M. Zuckerman and R.A. Rohde (eds.). Plant parasitic nematodes. vol. 3. Academic, New York.

Kimpinski, J. 1985. Nematodes in strawberries on Prince Edward Island, Canada. Plant Dis. 69:105-107.

McElroy, F.D. 1977. Distribution of stylet-bearing nematodes associated with raspberries and strawberries in British Columbia. Can. Plant Dis. Survey 57:3-8. 
Potter, J.W. and A. Dale. 1991. Root lesion nematode tolerance in wild and cultivated strawberry, p. 202-208. In: A. Dale and J.J. Luby (eds.). The strawberry into the 21 st century. Timber Press, Portland, Ore.

SAS Institute. 1989. SAS/STAT user's guide. 4th ed. Version 6. SAS Inst., Cary, N.C.

Scott, D.H. and F.J. Lawrence. 1975. Strawberries, p. 71-97. In: J. Janick and J.N. Moore (eds.) Advances in fruit breeding. Purdue Univ. Press, West Lafayette, Ind.

Sjulin, T.M. and A. Dale. 1987. Genetic diversity of North American strawberry cultivars
J. Amer. Soc. Hort. Sci. 112:375-385.

Steiner, G. 1931. Tylenchus pratensis de Man on tobacco, tomato, and strawberry. Plant Dis. Rptr. 15:106-107.

Szczygiel, A. 1981. Trials on susceptibility of strawberry cultivars to the root lesion nematode, Pratylenchus penetrans. Fruit Sci. Rpt. 8:115119.

Szczygiel, A. 1983. On the tolerance limit of strawberry plants to root lesion nematode Pratylenchus penetrans (Cobb). Fruit Sci. Rpt. 10:134-142.

Townshend, J.L. 1962. The root-lesion nematode, Pratylenchus penetrans (Cobb, 1917) Filip. \&
Stek., 1941, in strawberry in the Niagara Peninsula and Norfolk County in Ontario. Can. J. Plant Sci. 42:728-736.

Townshend, J.L. 1963a. The pathogenicity of Pratylenchus penetrans to strawberry. Can. J. Plant Sci. 43:75-78.

Townshend, J.L. 1963b. A modification and evaluation of the apparatus for the Oostenbrink direct cottonwool filter extraction method. Nematologica 9:106-110.

Vrain, T. 1985. Resistance to root-lesion nematode in strawberry. Can. Hort. Council Ann. Rpt. 1985:75. (Abstr.) 